\title{
Mercado y debilidad institucional
}

Juan Héctor Vidal

Miembro del Senado Consultivo

de la Universidad Tecnológica de El Salvador

Con frecuencia hemos dicho que al presidente Saca le ha tocado lidiar con el déficit acumulado -principalmente- durante las tres administraciones anteriores. Destacamos el "principalmente", porque ARENA ha tenido la oportunidad histórica -algunos dicen única- de transformar al país económicamente sin caer en excesos.

Fin

1 haber gobernado en un ambiente de paz, con amplio apoyo del sector privado y $\sin$ las restricciones que normalmente imponen a los países pobres las relaciones financieras internacionales -en este caso por el soporte que proveen las remesas familiares- han sido condiciones necesarias, pero no suficientes para enrumbar al país conforme al espíritu y la letra de los Acuerdos de Paz.

Infortunadamente el haber hecho de dichos Acuerdos un objetivo en si mismo y no un medio para impulsar las transformaciones que requiere el país para avanzar en su desarrollo integral, no sólo ha mediatizado el cambio, sino peor aún, ha ido reduciendo los espacios para trabajar alrededor de una visión compartida. Desde una perspectiva pragmática, el excesivo énfasis en las soluciones técnicas a problemas con un alto contenido social, ha sido además responsable de los pocos avances logrados en la construcción de un sistema económico sólido e incluyente.

Consiguientemente las transformaciones han sido solo relativas y más bien hoy en día los salvadoreños estamos viviendo un período donde el riesgo de involución, sale cada vez más perceptible y compartido. En esto no podemos ignorar la relación indisoluble entre la economía y la política. Los efectos de una gestión exitosa en el ámbito económico son por lo general poco apreciados en aquellas sociedades polarizadas como la nuestra, pero los errores cometidos en el ejercicio de la misma, se pagan siempre muy caro.

Ignorar ciertos avances en la dirección deseada, tampoco sería responsable. A pesar de todo, El Salvador ha hecho avances no despreciables en lo que concierne a la instauración de un modelo económico orientado hacia el mercado. En este sentido, incluso ha sido objeto de reconocimiento internacional. El Foro Económico Mundial así lo confirma y de manera contundente de le ubica en el segundo lugar en América Latina por su grado de libertad económica, después de Chile.

Sin embargo, en los hechos hay claras manifestaciones de que el sistema de precios no está funcionando en concordancia 


\section{Mercado y debilidad institucional}
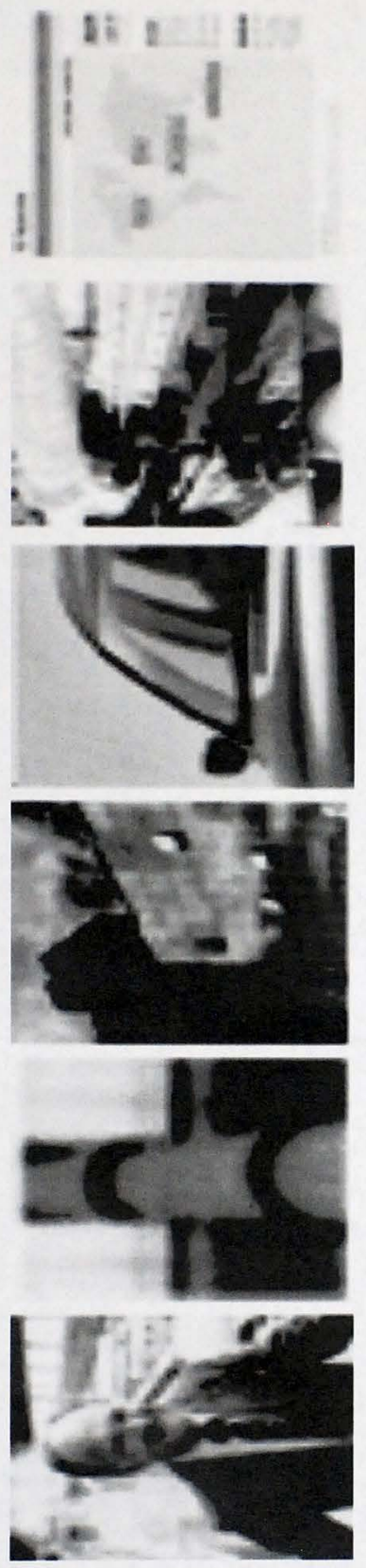

con los planteamientos teórico-conceptuales que sirvieron de base para impulsar la reforma económica. Es más, los enfoques sobre este punto son variados, aunque coincidentes en algunos casos.

Así por ejemplo, mientras la izquierda radical habla de que el "modelo neoliberal" ha fracasado otros más críticos -aunque paradójicamente separados ideológicamente de aquella por un enorme abismo- señalan que todo el problema se origina en que el sistema económico, tiene más de mercantilismo que de un sistema basado en la competencia.

Estos extremos invariablemente convergen en un solo punto: el rol del Estado en la economía. Ergo, gran parte de la explicación subyace en la forma en que el sistema económico se ha definido hacia lo privado. La diferencia estriba en que para unos el problema central se origina en la desaparición casi total del Estado, mientras que para otros, las dificultades emanan desde el momento en es que este existe para garantizarle privilegios a unos pocos

En el medio están los enfoques un poco más generosos. La crítica de estos gira en torno a la forma acrítica en que El Salvador siguió el recetario del Consenso de Washington, que entre otras cosas ponía mucho énfasis en la privatización. Aquí, el problema, sostienen algunos, es que también se confundieron medios con fines, donde las acciones estatales estuvieron más dirigidas a crear un escenario ideal para el desarrollo de los negocios que para el fortalecimiento del mercado como categoría económica. (FUSADES 2004)

Al referirse al punto, los defensores a ultranza del libre mercado con frecuencia aluden a la transformación que ha experimentado el país como pp. 10-14

Vidal, J. $\mathrm{H}$.

producto de la privatización de sectores estratégicos como el financiero, las telecomunicaciones y el de energía eléctrica. Y en realidad, a modernidad es evidente y hoy en día El Salvador cuenta en estos campos con servicios de categoría mundial. La pregunta es a qué costo y cuál sería el escenario si el proceso hubiera sido conducido bajo un enfoque menos ideológico y, por qué no decirlo, pensando mayormente en función de los intereses de determinados grupos.

Hablando específicamente de la privatización, las consecuencias están a la vista. Es cierto que debido al tamaño del mercado no se podía esperar que el proceso se realizara con apego irrestricto a las reglas de la competencia; esto ha sido incluso reconocido por organismos patrocinadores de la reforma económica como el Banco Mundial. Pero precisamente por esta misma razón, era indispensable la adopción de un marco regulatorio que previniera la entronización de prácticas anticompetitivas o se cayera en el extremo de permitir permanentemente la violación de los derechos de los consumidores.

A esas falencias se agrega el hecho, ahora generalmente reconocido, de que el proceso de privatización en general resultó desde el principio comprometido, porque los principales tomadores de decisiones fueron en algunos casos jueces y parte del mismo. El sector financiero es un caso emblemático, no sólo por la forma en que se rescataron financieramente los bancos, se condujo la transferencia a manos privadas, sino también por la integración horizontal y vertical que se dio con el paso del tiempo. En retrospectiva, esto se considera todavía más sensible con la venta de los principales conglomerados a grandes consorcios financieros internacionales.

El caso de las distribuidoras de ener- 


\section{Mercado y debilidad institucional}

gía eléctrica, las telecomunicaciones, los fondos de pensiones, confirma el aserto de que los consumidores, se encuentran en un total estado de indefensión. El de las petroleras, si bien es distinto en cuanto a que su origen siempre fue netamente privado, igualmente ha puesto en evidencia los abusos que se cometen en contra del consumidor, cuando el Estado carece de una institucionalidad adecuada y las presiones políticas se vuelven flexibles ante los intereses de grupos, aunque los generales y el mismo sistema político-económico resulten seriamente perjudicados.

En los hechos, todo se origina en la interrelación perversa que estamos observando entre la política y la economía, al extremo de mantener virtualmente secuestrada a la sociedad. Secuestrada en el sentido de que ninguna de las fuerzas políticas más importantes nos ofrece opciones, mientras tanto, el mercado, como categoría que supuestamente rige nuestra vida económica, sigue siendo odiada por algunos y venerada por otros.

Pero los problemas derivados de la permanente confrontación ideológica y sobre todo aquellos originados en el comportamiento de quienes que se han visto sido favorecidos por el manejo ortodoxo de la economía, no pueden razonablemente enfrentados en tanto la libertad, como tema central de la discusión, no sea suficientemente comprendida y el papel del Estado no haya sido claramente dilucidado.

La dificultad de reconocer la magnificencia de la libertad en el marco de las políticas públicas en una sociedad democrática, deriva de la necesidad de hacer un balance entre la libertad personal con las demandas ineludibles del orden social. En esencia estas dos categorías no deberías ser conflictivas, porque son parte de una dualidad del mismo problema.

Llevados estos conceptos al plano de la realidad nacional, podemos decir sin temor a equivocarnos es que hasta hoy es que los gobernantes empiezan a darse cuenta que en la construcción de una sociedad auténticamente democrática y libre, desde el punto de vista económico, las cosas no pueden quedar ni libradas a las decisiones arbitrarias de los políticos, ni a la ley de la selva para que el mercado lo haga todo.

Se dice que el actual gobernante, y hasta cierto punto nosotros tendemos a coincidir en ello, está tratando de enmendar los errores que se han cometido, como hemos dicho muchas veces, en nombre de una mal entendida libertad. Creo que la legislación en materia de competencia, la defensa de los derechos de los consumidores, la transparencia fiscal sin ahuyentar la inversión y las iniciativas en torno a una red de protección social, es parte importante de esa rectificación. La pregunta es si todavía estamos a tiempo.

Aunque la idea sobre el mercado y la institucionalidad surgió a raíz de las reacciones del propio Presidente de la República por la forma arbitraria con que se manejan los precios de los combustibles, nuestro interés en el tema no es nuevo. Creyentes como somos de la libertad económica, siem- pre hemos insistido en la necesidad de construir y perfeccionar permanentemente un sólido andamiaje institucional y jurídico que garantice la competencia y tutele los derechos de los consumidores. Esta es la única forma de prevenir y, en su caso castigar, las conductas impropias que tanto desprestigian al sistema.

Por ejemplo, a propósito de la aprobación de la Ley de Privatización de ANTEL, publicamos en nuestra columna en La Prensa Gráfica dos artículos consecutivos bajo el título: "Una ley de privatización no debería ser un cheque en blanco".

En el primero de ellos (23 de diciembre de 1996) y después de insistir en la necesidad de privatizar el sector en un marco de competencia, decíamos lo siguiente al referimos al enfoque que manejaban los funcionarios responsables del proceso: "Sin embargo, notamos cierta ingenuidad en algunos planteamientos cuando esa competencia se da por garantizada por el simple hecho de que tanto las acciones que adquirirán los socios estratégicos $(51 \%)$ y el resto de inversionistas -distintos de los trabajadores- (39\%) se someterán a subasta...Con un porcentaje de tal magnitud en el caso de los primeros, nadie puede garantizar que no habrá concertación de precios, mientras no podrá evitarse en el segundo caso, una fuerte concentración de acciones en pocas manos si se carece de mecanismos apropiados para prevenirla. Siendo así, nada impedirá la conformación de la típica figura monopólica y la consiguiente administración de las políticas tarifarias al libre albedrío de los socios mayoritarios".

\section{"Una ley de privatización no debería ser un cheque en blanco".}




\section{Haciendo}

un símil con lo que decía Churchill de la democracia, el sistema

\section{no es}

perfecto, pero es el menos malo de todos los conocidos.
Diez años después vale la pena recordar que a pesar de la fuerte promoción que se hizo de la privatización de los servicios de telecomunicaciones, al final sólo participó una empresa francesa, aunque para fines de "transparencia" se publicitó que habían varias otras interesadas, incluyendo una de origen mexicano que, según se dijo en su momento, a última hora había decidido no participar.

Posteriormente se supo que esta última estaba vinculada con la primera y, que entre los representantes de ambas empresas hubo contactos permanentes a través de un celular. Aún más, con la venta del paquete accionario que inicialmente se había reservado el Estado, el otrora monopolio público se convirtió, de hecho, en uno privado.

La forma en que se negociaron los contratos en el caso de las telecomunicaciones -igual que en el de las distribuidoras de energía eléctrica- ha sido un dolor de cabeza para el ente regulador, especialmente por las debilidades que marcaron su creación.

Además, hay un creciente rumor de que las sanciones impuestas por la SIGET a los operadores que infringen la ley, con frecuencia se caen en la Corte Suprema de Justicia, no tanto por la debilidad de los argumentos del ente regulador, cuanto por la presión que ejercen los prestadores de los servicios.

La decisión tardía de crear la Superintendencia de Competencia y la Defensoría del Consumidor, constituye también una expresión clara de los intereses que por largos años estuvieron torpedeando la edificación del andamiaje institucional y jurídico que requería el eficaz funcionamiento del sistema de precios. Infortunadamente, el tema ya ha trascendido a la esfera política, por el descrédito en que ha caído la gestión del modelo económico.
En toda esta discusión, hay que coincidir en una cosa. La economía de mercado tiene muchas virtudes, pero tampoco es inmaculada. Haciendo un símil con lo que decía Churchill de la democracia, el sistema no es perfecto, pero es el menos malo de todos los conocidos. Los problemas derivan de los excesos que se cometen en su nombre.

Y si de la experiencia salvadoreña se trata, los ejemplos abundan. El debate actual sobre los precios de los combustibles es un ejemplo típico de las situaciones que se dan en los mercados imperfectos -que en los hechos no son sino una desviación de una perfecta economía de libre mercado- cuando el Estado renuncia a su papel regulador.

En este caso particular, hasta la Asamblea Legislativa ha tenido que intervenir contratando los servicios de un experto internacional en la materia. Sin embargo, parece plausible que las presiones de los involucrados no se han hecho esperar. Se sabe que la Superintendencia de Competencia ya tenía un dictamen listo que tipificaba las prácticas anticompetitivas, cuando salió también a luz pública que la entidad, a petición de los afectados, había dado un año más para que defendieran su caso. Nosotros nos preguntamos ise necesita tanto tiempo para que empresas de tal categoría preparen adecuadamente su defensa, cuando han sido sistemáticamente señaladas por mucho tiempo como violadoras de las leyes del mercado?

Pero ese caso es solo uno más. Por ejemplo, por años el sector productivo, en particular el industrial, ha venido insistiendo en la necesidad de hacer más transparente el mercado energético, pero no fue sino hasta con las reformas que se introdujeron a la Ley General de Electricidad en el 2003 que se otorgó a la SIGET la facultad de "vigilar" el mercado. Mientras tanto se sigue sos- 


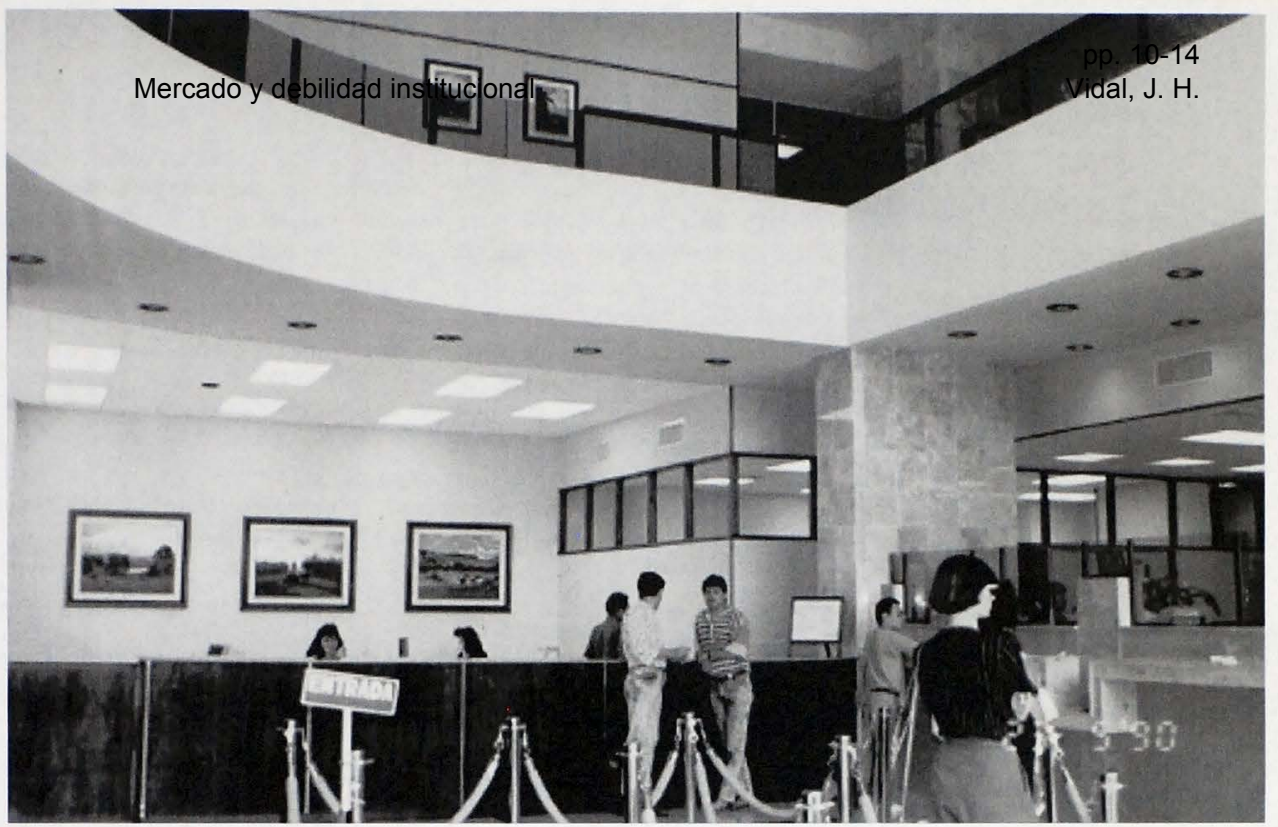

teniendo que el costo de la energía eléctrica en El Salvador es de los más altos del mundo.

Las implicaciones que tienen las distorsiones, por no decir abusos, que se dan en esos y otros sectores estratégicos - vía manipulación de los preciosen los costos de producción y la competitividad del país son enormes. Pero tampoco son despreciables los efectos que las prácticas abusivas, tienen en los bolsillos de las familias y más aún en el sistema político.

Se dice a menudo que el servicio más costoso es el que no se tiene. Sin duda esta aseveración popular tiene sentido, pero en una economía de mercado que funciona más o menos en concordancia con la teoría convencional, la soberanía del consumidor, como principio rector del mercado, no es un asunto trivial.

Por ello, tanto la Superintendencia de Competencia como la Defensoría del Consumidor tienen su razón de ser. El reconocimiento público que hizo recientemente el presidente del banco comercial más importante del país, acerca de cómo la intervención de Defensoría había incidido en la reducción -casi a la mitad- de las comisiones bancarias, es un buen ejemplo de que el mercado no puede quedar totalmente librado a las decisiones de los agentes económicos.

En casos como estos no creo que la intervención de la entidad haya vulnerado la libertad económica, aunque algunos fundamentalistas sostengan lo contrario. Y el caso de las comisiones bancarias es particularmente interesante, pues constituye una expresión clara hasta de de los errores conceptuales que se cometen cuando se habla inocentemente del sistema de precios. Por eso es que en lo que corresponde a la intermediación financiera, nosotros preferimos hablar del "costo del dinero tomado a préstamo" y no simplemente de la "tasa de interés, que es a la que normalmente se alude cuando se habla de competencia al interior del sector e incluso de los beneficios que ha traído la dolarización.
Pero en general, debemos aceptar que el atropello a los derechos de los consumidores y la presencia de prácticas anticompetitivas siguen allí, afectando en gran medida el funcionamiento del sistema y la credibilidad en el mismo, para regocijo de los defensores del intervencionismo estatal a ultranza.

En ese sentido, no deberíamos obviar las consecuencias que tienen en la pérdida del bienestar y la consolidación del sistema político, las prácticas reñidas con la ética empresarial, principalmente en los sectores estratégicos.

Discernir sobre estos aspectos, no sólo compete al gobierno; es tarea de todos los que creemos genuinamente en la democracia política y en la libertad económica. No entenderlo así, es como ignorar lo que está ocurriendo en el sur, comenzado por la sufrida Nicaragua.

Septiembre 2007, N. 39 